\title{
Social Attitudes of People Towards Adhering to Health Protocols to Prevent Covid-19 Infection
}

\author{
Hossein Esmaeili*1, Seyed Ali Hosseini Zavareh ${ }^{1}$, Maryam Mahdavi Afshar ${ }^{1}$, Zahra Salesi ${ }^{1}$, Zahra \\ Majdi $^{1}$, Mohammad Yavari ${ }^{2}$, Arman Nobakht ${ }^{1}$, Saba asgari ${ }^{2}$, Mostafa Bakhtiari ${ }^{2}$, Ehsan Babaei ${ }^{2}$ \\ and Ali Derakhti ${ }^{2}$
}

${ }^{1}$ Young Researcher and Elite Clube, Tehran Medical Sciences, Islamic Azad University, Tehran, Iran

${ }^{2}$ Bachelor of Science in Nursing, Islamic Azad University Tehran Medical Sciences, Tehran, Iran

*Corresponding author: Hossein Esmaeili, Young Researcher and Elite Clube, Tehran Medical Sciences, Islamic Azad University,

Tehran, 1916893813, Iran

\section{ARTICLE INFO \\ Received: 幽 November 14, 2020 \\ Published: 幽 November 24, 2020}

Citation: Hossein Esmaeili, Seyed Ali Hosseini Zavareh, Maryam Mahdavi Afshar, Zahra Salesi, et al. Social Attitudes of People Towards Adhering to Health Protocols to Prevent Covid-19 Infection. Biomed J Sci \& Tech Res 32(1)-2020. BJSTR. MS.ID.005205.

Keywords: Covid-19; Social Attitudes; Disinfectants; Mask; Health protocols against Covid-19

\begin{abstract}
Background: The use of masks is effective in reducing the incidence of covid-19 and can reduce the risk of transmission of Covid-19 disease through carriers or those who have not yet been diagnosed with symptoms. In some societies, however, it is common culture that only sick people wear masks. In addition to the mask, the World Health Organization has proposed two alcohol-based formulations for hand hygiene and reducing the prevalence and contamination of coronavirus in health care, but why do people not follow the health protocols regularly and seriously, despite having enough information about the conditions and dangers of this virus?
\end{abstract}

Methods: The present study is a cross sectional descriptive-analytical study that was conducted in the fall of 1399 (October and November 2020) on community members in Tehran. This study is organized in the form of two main axes of personal information and individuals' attitudes towards adhering to health protocols against Covid-19.

Results: According to the study, $78.3 \%$ of people use both masks and disinfectants, and only $6.4 \%$ believe that wearing a mask during the corona period is not necessary. In terms of gender segregation, women use masks more than men. Also, there is no exact relationship between the level of education and compliance with health protocols, so that people with a master's degree have the highest compliance with health protocols $(88 / 88=100 \%)$ and people with a doctorate have the lowest $(28 / 32=87 \%)$. About $18 \%$ of people do not use disinfectants that $26.31 \%(25 / 95=26.31 \%)$ of them believe that the use of disinfectants causes skin problems.

\section{Introduction}

According to the World Health Organization, the first human infection related to Covid-19 was registered in Wuhan, China in early December 2019 [1]. The World Health Organization, on the recommendation of IHR Emergency Committee on January 30, 2020, declared the outbreak as "public health emergencies of international concern (PHEIC) [2]. The disease spread rapidly and spread to most parts of the world, affecting almost all public places and different strata. Places that are considered high-risk areas for disease and have less health facilities include shops, sports clubs, exhibitions, nursing homes, prisons and psychiatric hospitals. It is estimated that about 14 million elderly people over 65 years in nursing homes and 10.74 million inmates in prisons [3,4], who are at higher risk due to fewer facilities. Also on February 8, 2020, in a report in a Chinese hospital, at least 50 patients with psychiatric disorders and 30 mental health professionals were infected with the virus [5], one of the reasons could be the irregular mental state of these people, which in itself reduces the observance of health protocols. According to research conducted in the United States, the virus has threatened many patients and operating room therapists and caused many problems for surgeons [6]. 
There are also many other such cases in various fields that have been studied by researchers. Following the outbreak of this disease, extensive research has been done to find a way to prevent and treat this disease. No vaccine is currently available, and treatment is mainly supportive. Measures should include avoiding unnecessary travel, identifying and isolating patients in the early stages, hand hygiene, respiratory hygiene, environmental hygiene, and social distance. The World Health Organization (WHO) has stated that SARS-Cov-2 is transmitted through airborne particles [7]. Van Doremalen et al. Stated that SARS-Cov-2 could survive for 3 hours in an aerosol less than $5 \mathrm{~mm}$ [8]. Due to the similar transmission characteristics between influenza and Covid-19, researchers consider the use of masks and hand hygiene to be the most effective way to prevent the disease [9-11]. In a research conducted in Taiwan, the use of masks has been shown to be effective in reducing the incidence of Covid-19 [12]. The use of masks was also effective in reducing the incidence of SARS 2003 [13,14]. Currently, the use of masks can reduce the risk of transmission of Covid-19 disease through carriers or those who have not yet been diagnosed with symptoms [15].

Indirect effects of mask use also include creating a social norm in society and increasing the level of risk perception, which can ultimately improve personal hygiene behaviors [16,17]. At one point, Us Surgeon General urged people to stop buying masks [18]. In addition, one of the reasons why people in some countries do not use masks is the limited supply of masks in health centers [19]. The shortage of supply of masks and the increase in demand has led to a significant increase in its price. This leads to the repeated use of disposable masks, which in turn increases the risk of Covid-19 disease [20]. The percentage of people in society who wear a mask during a pandemic depends on various factors, including culture. In some societies, it is common culture for only sick people to wear masks. In these societies, people are reluctant to wear masks and avoid wearing masks in order not to be identified as sick $[21,22]$ The World Health Organization has proposed two alcohol-based formulations for hand hygiene and reducing the prevalence and contamination caused by the Corona virus. These recommendations are based on rapid and effective antimicrobial activity as well as their widespread effectiveness [23]

However, some research shows that the use of disinfectants to prevent covid-19 is dangerous to the health of the environment and humans, and it is recommended that hands be washed frequently with soap and water to prevent possible contamination and infection [24]. Excessive ethanol consumption can cause Irritation, dryness or cracking of the skin, leading to symptoms such as redness and

Table 1: Frequency of people who use masks or disinfectants. itching of the skin. It can also cause skin cancer [25,26]. It is worth noting that in winter, many people may confuse the disease with the cold, which can lead to an arbitrary increase in antibiotic use [27]. Adherence to health protocols by people in different social classes can have a great impact on preventing or controlling the disease. But why do people not follow the health protocols regularly and seriously, despite having enough information about the conditions and dangers of this virus? In this article, we examine people's social perspectives on the use of masks and disinfectants, as well as the role of factors such as income level, age and gender in people's perspectives.

\section{Methods and Materials}

The present study is a cross sectional descriptive-analytical study that was conducted in the fall of 1399 (October and November 2020) on community members in Tehran. In this study, ethical considerations have been observed and after designing the questionnaire, members of the community have completed the questionnaire with their consent. All questionnaires are anonymous, and participants are assured of confidentiality. The questionnaire is organized in the form of two main axes of personal information and people's views on the observance of health protocols against Covid-19. The questionnaires were provided to the participants in person and after numbering each questionnaire, the coded information was extracted. For statistical analysis, SPSS 23 software is used.

\section{Results}

This study is conducted on 506 people, of which 241 (47.6\%) are male and 265 (52.4\%) are women. Most of the subjects are over 40 years old (42.5\%) With the bachelors' degree level (33.4\%). In addition, $8.1 \%$ of people less than 1 hour, $12.3 \%$ of people between 1 to 2 hours, and $17.8 \%$ of people between 2 to 4 hours, $29.4 \%$ of people between 4 to 8 hours and $32.4 \%$ of people more than 8 hours were outside the home in a Corona condition. About $78.3 \%$ of people use both masks and disinfectants, and only $6.4 \%$ believe that wearing a mask during corona is not necessary (Table 1). Our studies show that women use masks more than men (women96\% and men 90\%). There are no exact relationship between the level of education and observance of health protocols, so that people with a master's degree have the highest observance of health protocols $(88 / 88=100 \%)$ and people with a doctoral degree have the lowest $(28 / 32=87 \%)$. Then, people with diploma degree $(127 / 142$ $=89 \%)$, under diploma degree $(69 / 75=92 \%)$ and bachelor's degree $(161 / 169=95 \%)$ have the lowest level of health protocol compliance (Table 2).

\begin{tabular}{|l|c|c|c|c|}
\hline & $\begin{array}{c}\text { Frequency of those who } \\
\text { use only masks }\end{array}$ & $\begin{array}{c}\text { Frequency of those who } \\
\text { use only disinfectants }\end{array}$ & $\begin{array}{c}\text { Frequency of those who use both } \\
\text { masks and disinfectants }\end{array}$ & $\begin{array}{c}\text { Frequency of those who do not use } \\
\text { masks or disinfectants }\end{array}$ \\
\hline Frequency & 78 persons & 15 persons & 396 persons & 170 persons \\
\hline percentage & $15.4 \%$ & $3 \%$ & $78.3 \%$ & $4.3 \%$ \\
\hline
\end{tabular}


Table 2: The relationship between education and observance of health protocols.

\begin{tabular}{|c|c|c|c|c|c|}
\hline \multirow[b]{2}{*}{ Level of Education } & \multicolumn{4}{|c|}{ The use of masks or disinfectants } & \multirow[b]{2}{*}{ Total } \\
\hline & $\begin{array}{c}\text { Neither from mask nor } \\
\text { disinfectants }\end{array}$ & Only mask & Only disinfectants & $\begin{array}{l}\text { Both mask and } \\
\text { disinfectants }\end{array}$ & \\
\hline Under diploma & 5 & 22 & 1 & 47 & 75 \\
\hline Diploma & 8 & 17 & 7 & 110 & 142 \\
\hline Bachelor & 3 & 25 & 5 & 136 & 169 \\
\hline Master & 0 & 8 & 0 & 80 & 88 \\
\hline Doctoral & 2 & 5 & 2 & 23 & 32 \\
\hline Total & 18 & 77 & 15 & 396 & 506 \\
\hline
\end{tabular}

According to our results, older people use masks more, so that $96 \%$ of people over 40 use masks. This is while the rate of mask use in the age group of 20 to 29 years is about $84 \%$ (Table 3). According to the study, 360 people wore masks while away from home. However, 63 people used the mask only when crowded and 51 people only when they entered the closed space (Table 4). The main reason for not using the mask was "breathing hard while masking"

Table 3: Different reasons why people in the community do not use masks. and also the belief that "masking has no effect on preventing Corona disease". According to the data presented in Table 5, about $18 \%$ of people do not use disinfectants, of which $26.31 \%$ (25/95 = 26.31\%) believe that the use of disinfectants causes skin problems. After that, the main reasons for not using disinfectants, respectively, are "expensive disinfectants" and the idea that "hand washing alone is sufficient" (Table 5).

\begin{tabular}{|c|c|c|c|c|c|}
\hline $\begin{array}{c}\text { Reasons not to use a } \\
\text { mask }\end{array}$ & $\begin{array}{c}\text { Makes breathing } \\
\text { difficult }\end{array}$ & $\begin{array}{c}\text { It has no effect on } \\
\text { prevention }\end{array}$ & Its price is high & $\begin{array}{c}\text { It is difficult to } \\
\text { access }\end{array}$ & $\begin{array}{c}\text { Disinfectants alone are } \\
\text { sufficient }\end{array}$ \\
\hline Male & 11 & 10 & 1 & 1 & 1 \\
\hline Female & 8 & 2 & 1 & 0 & 1 \\
\hline Total & 19 & 12 & 2 & 1 & 2 \\
\hline
\end{tabular}

Table 4: Conditions in which people wear masks.

\begin{tabular}{|c|c|c|c|}
\hline When people wear masks & All the time they are out home & When they are crowded & When they enter the closed space \\
\hline Male & 151 & 38 & 30 \\
\hline Female & 209 & 25 & 21 \\
\hline Total & 360 & 63 & 51 \\
\hline
\end{tabular}

Table 5: Different reasons why people in the community do not use disinfectants.

\begin{tabular}{|c|c|c|c|c|c|c|c|}
\hline $\begin{array}{c}\text { Reasons } \\
\text { not to use } \\
\text { disinfectants }\end{array}$ & $\begin{array}{c}\text { Using a mask } \\
\text { alone is enough } \\
\text { for prevention }\end{array}$ & $\begin{array}{c}\text { Hand washing } \\
\text { is sufficient }\end{array}$ & Its price is high & $\begin{array}{c}\text { It is difficult to } \\
\text { access }\end{array}$ & $\begin{array}{c}\text { Its side effects } \\
\text { are many in } \\
\text { the long run }\end{array}$ & $\begin{array}{c}\text { Causes skin } \\
\text { problems }\end{array}$ & $\begin{array}{c}\text { It has no effect } \\
\text { on prevention }\end{array}$ \\
\hline Frequency & 14 & 23 & 24 & 4 & 8 & 25 & 8 \\
\hline
\end{tabular}

\section{Discussion}

According to the statistics obtained from the survey of questionnaires, it is observed that about $78 \%$ of people have used both masks and disinfectants, which is due to the prevailing conditions in the community and the high number of patients. It is reasonable. Compared to people who use only masks or only disinfectants, the number of people who use only masks is higher $15 \%$. According to research on the dangers of frequent contact with Detergents and disinfectants can be understood in the long run and their serious damage to the skin and increase a person's susceptibility to allergies [28]. It is better for people to use mild detergents as much as possible and without chemical and nonaromatic dyes. It is also recommended to use moisturizing or moisturizing creams after consuming these substances so that the destruction of skin tissue occurs less quickly.

Also, due to the fact that Covid 19 was not anticipated and considered, the increase in demand and lack of resources has led to an increase in prices, which also leads to a decrease in the purchasing power of people in the community. On the other hand, $37 \%$ of the participants believed that using a mask and hand washing alone would suffice, which would increase the level.

Clarifies information and awareness in the community. According to studies, there are several reasons for not using a mask. For example, some people with a degree below the diploma, scientific and medical aspects do not understand the need to use a mask to prevent the spread of the virus in the environment 
and disease transmission. They avoid wearing masks, believing that most people they meet and interact with on a daily basis in different places are in seemingly healthy physical condition, but may in fact be carriers of the disease. Of course, a large percentage of the participants had a relatively good awareness, which could indicate that the government and the media have done some good work in raising public awareness. Also, according to the results, it was observed that about $3.3 \%$ of people, regardless of any level of science, finance, age, etc. do not use any masks and disinfectants. Two women and 15 men (when talking to these people, it became clear that they were mostly young people in the community and believed that due to having a strong immune system, if infected, they would have a mild form of the disease and their serious risks However, these people should be aware that in case of infection they may not have any symptoms and by not following the protocols, they may spread the disease.

However, this percentage will be a little worrying in larger statistical populations. Adequate information, information and education about the disease and methods of prevention and transmission should be given to the people so that changing the attitudes of those few people will eventually lead to a change in their behavior and encourage them to follow health protocols. In this way, in addition to their own health, the health of others is largely guaranteed. In the meantime, special attention should be paid to the cultural factor. In societies where it is believed that only suspicious and carriers or patients wear masks and there is stigma and discrimination, many people avoid wearing masks [29]. Even in studies $[30,31]$ it has been stated that some employers in highrisk environments such as grocery stores, etc., stop their employees from wearing masks. Another reason for not using a mask, especially for older people who also have underlying diseases, is shortness of breath and the general belief that it has no effect on prevention. However, according to the results recorded in related articles, the use of masks in older people has been reported more than young people.

In our study, people 40 years old about $4 \%$ more than people between 20-40 years old use masks This statistic can be partly due to the fact that older people are at higher risk due to diseases and weakened immune systems. Of course, we know that the use of masks in all age groups, especially indoors is essential [32]. According to the statistical studies and calculations obtained from the questionnaire, similar to the results of most other articles, we find that women are more likely than men to use masks and disinfectants [33]. Our statistics show 220 people make up more than $50 \%$ of women who use both masks and disinfectants, and women have a higher rate of menopause than ever before. It can be due to the normalization of the condition and more inattention of men to the disease. If we want to find out more precisely and psychologically the cause of this issue, we can refer to research done in previous pandemics such as SARS and H1N1 These studies showed that men try to overcome their fears and do not wear masks because of social and psychological taboos and with the view that masking is a sign of weakness and fear [34,35]. According to the results of some studies, it can be said that blood type A should follow health protocols more than others [36].

\section{Conclusion}

The incidence of covid-19 is increasing daily around the world, and one of the most important reasons is the lack of compliance with health protocols by people in the community. In Iran, most people use both masks and disinfectants, but the number of patients is still high, which can be due to various reasons such as "the quality of the masks" and "lack of proper use of how to put and remove the mask" and so on which needs more research. The main reason why people in the community do not use the mask is that "wearing a mask makes it harder to breathe", as well as this believe that the use of disinfectants can cause skin problems. It is suggested that the media place more serious emphasis on this disease and increase the level of public awareness in the field so that this disease is taken more seriously and health protocols are followed in the right way.

\section{References}

1. (2019) World Health Organization. WHO Novel Coronavirus - China.

2. Ramesh N, Siddaiah A, Joseph B (2020) Tackling corona virus disease 2019 (COVID 19) in workplaces. Indian Journal of Occupational and Environmental Medicine 24(1):16.

3. Lloyd Sherlock PG, Kalache A, McKee M, Derbyshire J, Geffen L, et al. (2020) WHO must priorities the needs of older people in its response to the covid-19 pandemic. BMJ 368.

4. (2019) United Nations. World Population Ageing: Highlights. Department of Economic and Social Affairs, Population Division, New York.

5. (2020) China News Weekly. Hospital-acquired infection in Wuhan Mental Health Center: around 80 medical staff and patients were diagnosed with 2019-nCoV pneumonia.

6. Dexter F, Parra MC, Brown JR, Loftus RW (2020) Perioperative COVID-19 defense: an evidence-based approach for optimization of infection control and operating room management. Anesthesia and Analgesia.

7. (2020) World Health Organization. Modes of transmission of virus causing COVID-19: Implications for IPC precaution recommendations: Scientific brief.

8. Van Doremalen N, Bushmaker T, Morris DH, Holbrook MG, Gamble A, et al. (2020) Aerosol and surface stability of SARS-CoV-2 as compared with SARS-CoV-1. New England Journal of Medicine 382(16): 1564-1567.

9. Aiello AE, Murray GF, Perez V, Coulborn RM, Davis BM, et al. (2010) Mask use, hand hygiene, and seasonal influenza-like illness among young adults: a randomized intervention trial. The Journal of infectious diseases 201(4): 491-498.

10. Jefferson T, Foxlee R, Del Mar C, Dooley L, Ferroni E, et al. (2008) Physical interventions to interrupt or reduce the spread of respiratory viruses: systematic review. Bmj 336(7635): 77-80.

11. Leung NH, Chu DK, Shiu EY, Chan KH, McDevitt JJ, et al. (2020) Respiratory virus shedding in exhaled breath and efficacy of face masks. Nature medicine 26(5): 676-680.

12. Wang CJ, Ng CY, Brook RH (2020) Response to COVID-19 in Taiwan: big data analytics, new technology, and proactive testing. Jama 323(14): 1341-1342.

13. Lau JT, Tsui H, Lau M, Yang X (2004) SARS transmission, risk factors, and prevention in Hong Kong. Emerging infectious diseases 10(4): 587. 
14. Wu J, Xu F, Zhou W (2004) Risk factors for SARS among persons without known contact with SARS patients, Beijing, China. Emerg Infect Dis 10 210-216.

15. Chan KH, Yuen KY (2020) COVID-19 epidemic: disentangling the reemerging controversy about medical facemasks from an epidemiological perspective. International Journal of Epidemiology.

16. MacIntyreCR, CauchemezS, DwyerDE (2009) Face mask use and control of respiratory virus transmission in households. Emerg Infect Dis 15: 233-241.

17. Lau JT, Kim JH, Tsui HY, Griffiths S (2008) Perceptions related to birdto-human avian influenza, influenza vaccination, and use of face mask. Infection 36: 434-443.

18. (2020) CDC. Coronavirus Disease 2019 (COVID-19): steps to prevent illness.

19. (2020) Federal Ministry of Health, Germany. Daily updates on the coronavirus: is wearing a surgical mask, as protection against acute respiratory infections, useful for members of the general public? 2020.

20. (2020) Ministry of Health, Labour and Wellfare, Japan. Q \& A on coronavirus 2019 (COVID-19): when should I wear a facemask?

21. K Abney (2018) Containing tuberculosis, perpetuating stigma: the materiality of n95 respirator masks. Anthropol. South Afr 41: 270-283.

22. E Buregyeya (2012) Acceptability of masking and patient separation to control nosocomial tuberculosis in Uganda: a qualitative study. J Public Heal 20: 599-606.

23. (2020) World Health Organization. WHO guidelines on hand hygiene in health care: first global patient safety challenge clean care is safer care. Geneva.

24. Mahmood A, Eqan M, Pervez S, Alghamdi HA, Tabinda AB, et al. (2020) COVID-19 and frequent use of hand sanitizers; human health and environmental hazards by exposure pathways. Science of the Total Environment 742: 140561

25. Lachenmeier DW (2008) Safety evaluation of topical applications of ethanol on the skin and inside the oral cavity. Journal of Occupational Medicine and Toxicology 3(1): 26.

26. (2016) NewJersey Department of Health (NJH), Hazardous substance fact sheet (ethyl alcohol).

\section{ISSN: 2574-1241}

DOI: $10.26717 /$ BJSTR.2020.32.005205

Hossein Esmaeili. Biomed J Sci \& Tech Res

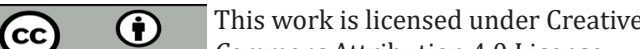

Commons Attribution 4.0 License

Submission Link: https://biomedres.us/submit-manuscript.php
27. Hesam Aldin Varpaei, Hossein Esmaeili, Mohammad Yavari, Mohammad Mahdi Miremami, Amir Mahdi Farahani, et al. (2020) Epidemiological Study of Antibiotic Self-Medication in Tehran 1399: A Descriptive Study. Biomed J Sci \& Tech Res 31(1).

28. Mac Gibeny, Margaret A, Cindy Wassef (2020) Preventing adverse cutaneous reactions from amplified hygiene practices during the COVID-19 pandemic: how dermatologists can help through anticipatory guidance. Archives of Dermatological Research.

29.|Howard, Jeremy (2020) Face masks against COVID-19: an evidence review.

30. (2020) Tampa Bay nurses were told not to wear masks in hallways. Now hospitals are changing the rules.

31. S Malone (2020) NY Correctional Officers Ordered Not To Wear Masks, Even If They Have Them. Maven.

32. Haischer, Michael H (2020) Who is wearing a mask? Gender-, age-, and location-related differences during the COVID-19 pandemic. PloS one 10: e0240785.

33. Garima, Annabelle Santos, Erin D (2020) Sex differences in mortality from COVID-19 pandemic: are men vulnerable and women protected? JACC: Case Reports 2(9): 1407-1410."

34. Scheid JL, Lupien SP, Ford GS, West SL (2020) Commentary: Physiological and Psychological Impact of Face Mask Usage during the COVID-19 Pandemic. International Journal of Environmental Research and Public Health 17(18): 6655 .

35. Mahmood A, Eqan M, Pervez S, Alghamdi HA, Tabinda AB, et al. (2020) COVID-19 and frequent use of hand sanitizers; human health and environmental hazards by exposure pathways. Science of the Total Environment 742: 140561 .

36. Mostafa Mohammadi, Hesam Aldin V, Majid Amini, Hossein Esmaeili (2020) Investigating the Relationship Between Clini-cal Characteristics of 2019 Novel Coronavirus Pneumonia Cases (COVID-19) Before Intubation and Treatment Outcome After 14 Days in Imam Khomeini Hospital Complex, Tehran, Iran: Descriptive-Analytic Study. American Journal of Biomedical Science \& Research 10(5): 478-489.

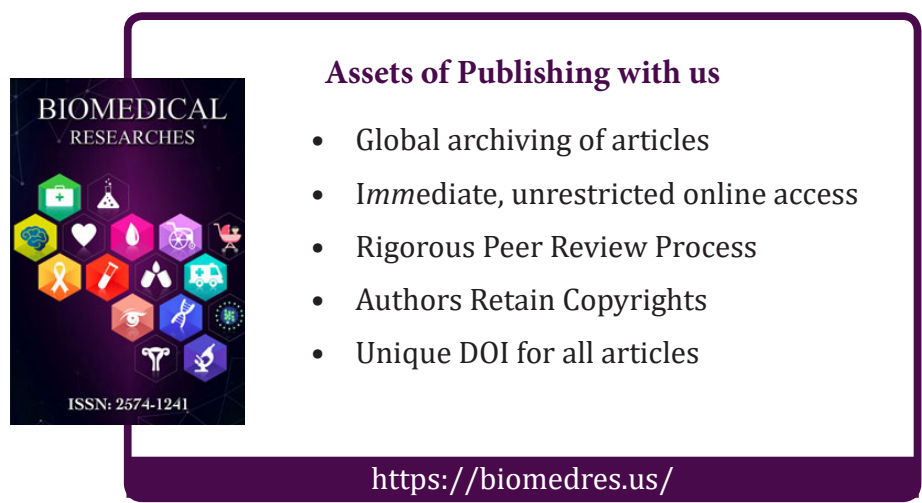

